\title{
CONTRATOS, CONVÊNIOS E PARCERIAS NA GESTÃO DA EDUCAÇÃO EM MUNICÍPIOS DE REGIÕES METROPOLITANAS: TENSÕES E DESAFIOS
}

\author{
Angela Maria Martins* \\ Cláudia Oliveira Pimenta** \\ VALÉRIA VIRGÍNIA LOPES ${ }^{* * *}$
}

\begin{abstract}
RESUMO: Este artigo discute resultados de estudo-piloto que apresentava como propósito examinar a capacidade institucional de dez municípios paulistas na gestão da educação básica. Na investigação original, os dados foram sistematizados e agregados em torno de cinco categorias de análise, a saber: estrutura e funcionamento do sistema/rede de ensino; gestão de pessoas; gestão pedagógica; financiamento e, finalmente, a quinta categoria - programas e projetos - estruturada com base na análise da realização de convênios, contratos e parcerias com os governos, federal e estadual; outros municípios; o setor privado lucrativo e não lucrativo; universidades; outras secretarias e/ou órgãos da administração municipal. Foram considerados também os programas e projetos implementados por iniciativa da própria Secretaria/Diretoria de educação e de suas equipes. Este artigo focará estas últimas questões.
\end{abstract}

Palavras-chave: Políticas municipais de educação. Capacidade institucional. Programas e projetos de governo.

\section{CONTRACTS, GRANTS AND PARTNERSHIPS IN EDUCATION \\ MANAGEMENT IN MUNICIPALITIES AND METROPOLITAN REGIONS: TENSIONS AND CHALLENGES}

ABSTRACT: This article discusses the results of a pilot study which aimed at examining the institutional capability of ten cities in the state of São Paulo, Brazil in managing basic education. In the original investigation, the data were systematized and brought together into five categories: structure and functioning of the teaching system/network; human resources management; pedagogical management; financing and programs and projects. The last category was

\footnotetext{
* $\quad$ Mestrado em Educação da Universidade Cidade de São Paulo (Unicid). São Paulo (SP) - Brasil.

** Fundação Carlos Chagas (FCC). São Paulo (SP) - Brasil.

*** Fundação Carlos Chagas (FCC). São Paulo (SP) - Brasil.

Contato com os autores: <ange.martins@uol.com.br>
} 
Contratos, convênios e parcerias na gestão da educação em municípios...

structured according to criteria based on the analysis of contracts, grants and partnerships with the federal and state governments, other municipalities, the private sector (for-profit or non-profit), universities, other secretariats and/ or organs belonging to the municipal administration. Programs and projects implemented by the own Education Secretariat/board and their staff were also considered. This article will focus on the latter aspects.

Key words: Municipal education policies. Institutional capability. Government programs and projects.

\title{
Contrats, ACCORdS ET PARTENARIATS DANS LA GESTION DE \\ L'ÉDUCATION DANS DES VILLES DE RÉGIONS MÉTROPOLITAINES: TENSIONS ET DÉFIS
}

\begin{abstract}
RÉSUMÉ: Cet article discute les résultats de l'étude-pilote qui présentait comme intention examiner la capacité institutionnelle de dix villes de l'Etat de São Paulo dans la gestion de l'enseignement de base. Dans la recherche originale, les données ont été systématisées et ajoutées autour de cinq catégories d'analyse, à savoir: structure et fonctionnement du système/réseau d'enseignement; gestion du personnel; gestion pédagogique; financement et, finalement, cinquième catégorie - programmes et projets - structurée sur l'analyse de la réalisation d'accords, de contrats et de partenariats avec les gouvernements fédéral et de l'état; autres villes; le secteur privé lucratif et non lucratif; universités; autres secrétariats et/ou des agences de l'administration de la municipalité. Aussi, ont été considérés les programmes et les projets mis en œuvre par l'initiative de la Direction et du Secrétariat d'éducation et de leurs équipes. Cet article met en évidence ces dernières questions.
\end{abstract}

Mots-clés: Politiques municipales d'éducation. Capacité institutionnelle. Programmes et projets du gouvernement.

\section{Pressupostos teóricos e metodológicos do estudo ${ }^{1}$}

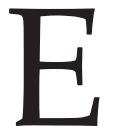

ste estudo tomou como pressuposto que decisões registradas em agendas de governo são articuladas em determinado período histórico, negociadas por entrelaçamentos de interesses, ampliando a complexidade de entendimento sobre o que o governo faz, para quem e por que, pois coloca em evidencia novos atores sociais: ${ }^{2}$ o Estado, que abriga grupos de interesses de funcionários públicos; organizações não governamentais, entidades sindicais e grupos representativos de interesses específicos, tais como os que defendem o direito às diferenças, entre outros.

Assim, assumimos que as políticas públicas são traduzidas em ações que se realizam em processo, durante o qual negociações são encetadas e grupos em conflito influenciem a agenda de governo. Nessa perspectiva, os processos de implementação podem assumir, na visão de alguns autores, maior importância do que as formulações de agenda, pois é no seu decorrer que as políticas ganham dinâmica, mudam, são reorientadas e renegociadas (FREY, 2000). ${ }^{3}$ Entretanto, apesar de a pesquisa não 
se configurar como estudo de implementação, alguns dos elementos que compõem esse tipo de abordagem - tais como os já assinalados - serviram de referência para a análise aqui encetada.

Nesse sentido, podem compor o campo de análise da capacidade institucional de municípios aspectos tais como as características organizacionais, no que tange: à estrutura legal e normativa de redes/sistemas de ensino; à gestão de recursos humanos; ao uso de dados e informações pelos municípios para monitorar/avaliar sua política educacional; às atividades-meio (gestão pedagógica) e às relações intergovernamentais.

Acrescente-se que, tendo em vista a heterogeneidade das redes de ensino (nas cidades maiores, há cobertura da rede estadual, municipal e privada, esta última nicho de emprego para os professores que dobram ou triplicam sua jornada de trabalho), torna-se tarefa complexa para os municípios arcarem com a ampliação do atendimento com qualidade e a respectiva valorização dos profissionais. Esse processo depende da capacidade de geração de recursos locais, da arrecadação tributária, enfim, das características econômicas, demográficas e políticas de cada município. Ademais, no caso do estado de São Paulo, especificamente, a Secretaria de Estado da Educação possui estrutura e capacidade administrativa para formular uma agenda política configurada por estratégias indutoras capazes de mobilizar os municípios paulistas em processos de parcerias e convênios no campo educacional (MARTINS, 2010).

Em suma, considerando desenhos híbridos que vêm sendo configurados nos estudos de diferentes programas e projetos governamentais, a investigação partiu do pressuposto de que, após a Constituição de 1988 e, sobretudo no estado de São Paulo, após o processo de municipalização, consolidado por meio de convênio entre a Secretaria de Estado da Educação de São Paulo (SEE-SP) e municípios, desde 1996 -, estes entes federados poderiam ter construído dinâmicas de planejamento e gestão das políticas públicas que atendessem de maneira mais equânime a educação básica.

\section{O contexto do estudo-piloto: regiões metropolitanas em destaque ${ }^{4}$}

Inicialmente, é preciso ressaltar a relevância de se estudar as regiões metropolitanas (RMs), tendo em vista, da perspectiva histórica, o processo de instituição das primeiras RMs no Brasil - entre os anos 1960 e 1970 - configurando, até os dias atuais, cerca de 30 áreas metropolitanas, localizadas nas cinco regiões do país.

Em função de terem sido criadas durante a vigência do regime militar - impostas autoritariamente -, passaram a ser vistas com muita cautela por estudiosos que questionam critérios e especificidades adotados para sua configuração, mesmo 
Contratos, convênios e parcerias na gestão da educação em municípios...

após as diretrizes democráticas e descentralizadoras da Constituição de 1988. Após sua promulgação, as instâncias estaduais definiram critérios para institucionalizar uma RM, induzindo a uma diversidade de parâmetros sem precedentes, tendo em vista a heterogeneidade econômica, política, social e de densidade demográfica das diversas regiões do país.

Entretanto, a literatura da área aponta os principais problemas e limites no que tange às especificidades dessas regiões, indicando, concomitantemente, potencialidades referentes à institucionalidade e refinamento nos instrumentos de planejamento regionais, possíveis em função da autonomia dos estados para legislar sobre esses territórios.

A expressão "região metropolitana" surgiu, primeiramente, na Constituição Federal de 1967, artigo n. 164, definindo que a União, mediante lei complementar, poderia estabelecer regiões metropolitanas constituídas por municípios que, independentemente de sua vinculação administrativa, integrassem a mesma unidade socioeconômica, visando a realização de serviços comuns. ${ }^{5}$ Em 1973, a Lei Complementar n. 14 criou as primeiras regiões metropolitanas do país: São Paulo, Belo Horizonte, Porto Alegre, Recife, Salvador, Curitiba, Belém e Fortaleza, determinando que cada uma delas teria um Conselho Deliberativo e um Conselho Consultivo, estabelecidos por lei estadual.

Em 1974, foram criadas a Região Metropolitana do Rio de Janeiro e a Comissão Nacional de Regiões Metropolitanas e Política Urbana (CNPU), ligada à Secretaria de Planejamento da Presidência da República, com participação de representantes dos Ministérios da Fazenda, Indústria e Comércio, Transportes e Interior. A finalidade do órgão era acompanhar a implantação do sistema de regiões metropolitanas e propor diretrizes, estratégias e instrumentos da política nacional de desenvolvimento urbano, além de avaliar sua execução.

Nos anos seguintes, os fatos mais importantes foram a criação do Fundo Nacional de Desenvolvimento Urbano (FNDU), em 1975, abastecendo a CNPU de recursos a serem aplicados nos programas de desenvolvimento urbano; o início da elaboração dos Planos de Desenvolvimento Integrado das Regiões Metropolitanas (1976) e a substituição da CNPU pelo Conselho Nacional de Desenvolvimento Urbano (CNDU), em 1979. Ainda em 1979, foi alterada a composição do FNDU, o que reduziu a possibilidade de administrar recursos de forma mais integrada, limitando o CNDU à elaboração de instrumentos normativos para a gestão urbana e metropolitana.

Em 1980, o CNPU, em conjunto com as entidades metropolitanas e instituições estaduais de meio ambiente, esforçou-se na definição de parâmetros de zoneamento industrial que subsidiariam as futuras diretrizes ambientais do país. Em 1981, 
o Decreto n. 85.916 preconizou a consolidação do sistema metropolitano brasileiro, o que, de acordo com o documento, "reforçou o caráter coordenador do CNDU e a necessidade de compatibilização dos planos e programas do governo federal com os planos de desenvolvimento integrado das regiões metropolitanas". ${ }^{6}$ No entanto, o órgão já estava com sua capacidade de ação comprometida devido à passagem do CNDU para o Ministério do Interior.

Com a promulgação da Constituição de 1988, a criação das regiões metropolitanas passa para o âmbito do Estado, conforme preconiza o artigo 25. Entretanto, a Constituição trouxe poucos avanços para as RMs, tendo em vista que não definiu sua organização política e administrativa, tampouco prescreveu funções de gestão, transferindo aos entes federados a competência de institucionalizá-las. Um dos avanços pós-Constituição de 1988, porém, diz respeito à ampliação da participação da sociedade na gestão dos espaços metropolitanos. Assim, em 1995, criou-se o Fórum Nacional de Entidades Metropolitanas, com reuniões regulares para a discussão de temas relacionados à questão das metrópoles. Essas reuniões possibilitam a avaliação do processo de evolução da gestão metropolitana nas diversas regiões do país, que vem sendo realizada em etapas similares ao longo do tempo.

A primeira, implantada e implementada de forma centralizada pela União, ajustou-se às políticas nacionais de planejamento integrado, que se pautava - à época do regime militar - pela coordenação das ações dos diversos níveis de governo nas áreas urbanas. Na segunda etapa - marcada pela abertura política dos anos de 1980 - os órgãos metropolitanos perderam espaço, reduzindo suas instituições; as próprias áreas metropolitanas, identificadas com o período autoritário, passaram a ter sua função questionada. A terceira etapa - iniciada nos anos de 1990 - foi marcada por novas atribuições dadas às instituições metropolitanas, pautadas pela realização de ações conjuntas entre os municípios metropolitanos.

No que diz respeito às diferentes noções relacionadas às regiões metropolitanas, destaque-se a análise realizada por Freitas (2009). O autor aborda a instituição das primeiras RMs no Brasil, entre os anos de 1960 a 1970, e discorre sobre as cerca de 30 áreas metropolitanas atuais, localizadas nas cinco regiões do país, juntamente com as três Regiões Integradas de Desenvolvimento (Ride), que abrangem municípios pertencentes a mais de uma unidade da Federação.

Para o autor, as regiões metropolitanas representam um fenômeno físico e socioeconômico, formado pela combinação dos processos de urbanização, metropolização e conurbação. As RMs foram institucionalizadas com o objetivo de possibilitar a gestão de problemas comuns a mais de um município. Entre os princípios referenciais para a caracterização de uma RM, Freitas (2009) assinala que estas devem possuir uma concentração populacional urbana igual ou superior a 1 milhão de habitantes; apresentar conurbação (quando não há limite entre os municípios limítrofes); grau 
Contratos, convênios e parcerias na gestão da educação em municípios...

de urbanização igual ou superior a $80 \%$; densidade demográfica igual ou superior a 60 habitantes $/ \mathrm{km}^{2}$; participação formal nos setores de indústria, comércio e serviços igual ou superior a $65 \%$ do total de pessoas empregadas; polarização em uma rede de cidades; destaque no estado e no país devido à oferta de bens e serviços diversificados e especializados; existência de relação funcional de interdependência em aspectos sociais, econômicos, de infraestrutura e de serviços.

No que tange à normatização das regiões metropolitanas, Maricato (2011) assinala o que pode ser considerado um consenso entre pesquisadores e técnicos acerca da precariedade do quadro legal das regiões metropolitanas no país. Com a promulgação da Constituição de 1988, coube aos estados a definição de critérios para institucionalizar uma RM, o que levou a uma diversidade de parâmetros, opondo-se ao cenário anterior, no qual, durante a ditadura, essa definição havia sido elaborada de forma autoritária por imposição de lei federal. ${ }^{7}$ Tal diversidade levou a um conjunto heterogêneo de RMs, "dentro do qual figuram aglomerações urbanas com importância demográfica, econômica, social e política bastante diferenciada" (p. 10). Para a autora, nem a forma autoritária de impor as RMs, adotadas pelo regime militar, nem a orientação democrática e descentralizadora da Constituição de 1988 conduziram a resultados satisfatórios na gestão metropolitana.

Apesar do caráter antidemocrático verificado na definição das nove RMs pelo governo federal nos anos 1970 (a gestão das regiões foi deixada a cargo de um conselho deliberativo constituído majoritariamente por representantes indicados pelo governo federal e estadual), Maricato (2011) considera que se formaram, à época, alguns dos mais importantes organismos de planejamento metropolitano, principalmente pela disponibilização de fundos destinados a obras de habitação e infraestrutura urbana.

Assim como a Constituição de 1988, o Estatuto da Cidade, Lei Federal n. 10.257 - uma conquista do movimento social defensor da agenda da reforma urbana -, não deu grande atenção às metrópoles. Um dos principais motivos apontados pela literatura da área está relacionado à herança centralizadora que impactou negativamente o debate sobre as RMs. Apesar disso, houve a busca de caminhos cooperativos entre os entes federados, como os consórcios, que procuram solucionar problemas comuns a mais de um município. Nesse cenário, Maricato (op. cit.) destaca o Consórcio da Região do Grande $\mathrm{ABC}$, criado por sete prefeitos daquela região nos anos de 1990, que inspirou a elaboração da Lei dos Consórcios Públicos, em 2005. Entretanto, logo após a promulgação da referida Lei, o movimento social da reforma urbana passou a perder força, o que fragilizou também os consórcios, que se reduziram a políticas setoriais.

Com relação à institucionalização de entidades administrativas metropolitanas, tendo em vista que na maior parte dos casos estas são criadas e implementadas 
de cima para baixo, o quadro analisado pela autora não é melhor, pois apenas sete apresentam estruturas institucionalizadas para promover a gestão metropolitana. Os formatos mais recorrentes são órgãos, tais como agências de desenvolvimento, fundos metropolitanos e conselhos de desenvolvimento. Entretanto, nenhuma das RMs com essas estruturas

[...] apresenta uma satisfatória experiência de integração administrativa, especialmente se considerarmos o tema central de controle sobre o uso e ocupação do solo que está relacionado aos grandes problemas vividos pelas metrópoles: sociais, ambientais, de saneamento, de transportes, de drenagem, de saúde e de segurança. (MARICATO, 2011, p. 17)

No mesmo sentido, Gouvêa (2009, p. 47) sustenta que as RMs do país não dispõem de arranjos institucionalizados para "efetivar a formulação, implementação e controle de políticas públicas plurimunicipais". As principais razões para isso seriam a compreensão rígida de autonomia municipal, o que dificulta o desenvolvimento da evolução da economia regional, e a assimetria nas relações de poder entre os municípios das RMs, visto que na maior parte delas há o que se chama de "megamunicípios".

Gouvêa (2009) cita também os consórcios públicos, regulamentados em lei e implementados por gestores públicos para solucionar problemas comuns entre municípios contíguos. Considera que, se os consórcios têm potencial para criar condições à promoção de políticas públicas metropolitanas, não avançam na criação de políticas que não sejam do interesse dos municípios maiores, tais como as políticas compensatórias, pois não tocam na questão da autonomia municipal.

De qualquer forma, os consórcios têm sido apontados pela literatura da área como possibilidade de superação dos problemas que enfrentam, pois estes ultrapassam seus territórios. Assim, esses novos arranjos de cooperação municipal podem "permitir ganhos de escala nas políticas sociais, além de ser um novo modelo gerencial que pode viabilizar a gestão microrregional das políticas públicas" (CRUZ; MONTORO; BIO, 2001, p. 134).

No estado de São Paulo, foram estruturados cinco consórcios intermunicipais de saúde - desativados - e dez em funcionamento; dois consórcios em funcionamento na área de assistência social e um desativado na educação, todos eles na forma de sociedade civil sem fins lucrativos. O consórcio desativado na área de educação foi criado nos anos de 1990, na região de São João da Boa Vista, com sede em Casa Branca, "com a finalidade de planejar as ações de educação, com intuito de melhoria do ensino fundamental, com o apoio da Fundação de Desenvolvimento da Universidade do Estado de São Paulo - Fundunesp" (ibid., p. 141).

Registre-se o modelo de gestão construído na Região Metropolitana de Campinas, com a criação do Conselho de Desenvolvimento, da Agência Metropolitana 
de Campinas (Agemcamp) e das Câmaras Temáticas, complementado com a criação do Plano Metropolitano de Saúde, uma complexa ação que orientou a produção de uma matriz de implementação de projetos metropolitanos (PERES; ZIMMERMANN, 2010).

Na Região Metropolitana da Baixada Santista, Lippi (2009) analisa a articulação intergovernamental, tendo como referência a realização de estudo de caso da Agência Metropolitana da Baixada Santista (Agem). A autora argumenta que as áreas metropolitanas reforçam a necessidade de fomentar e promover a integração entre diferentes atores governamentais, salientando que as agências metropolitanas são órgãos que viabilizam a intersetorialidade e a articulação intergovernamental, já que estão vinculadas aos governos estaduais, articulam diversos municípios e respondem a diretrizes vindas do governo federal.

\section{Os estudos de campo}

Inicialmente, alguns questionamentos deram origem à investigação, sobretudo no que diz respeito à estrutura física, administrativa e de recursos humanos disponíveis para a gestão da educação no âmbito municipal; ao volume de recursos orçamentários para a área de educação e mecanismos de controle desses recursos; às fontes de dados e informações para o planejamento da política educacional local; às modalidades de convênios e parcerias realizadas entre o município, a esfera estadual e a esfera federal, bem como com o setor privado lucrativo e não lucrativo; aos mecanismos e dinâmicas de monitoramento e avaliação da implementação de diretrizes legais/medidas, programas e projetos próprios ou conveniados; às estratégias utilizadas pelos governos municipais para promover a gestão participativa.

Entretanto, ao final do percurso, alguns dos questionamentos iniciais - submetidos à realidade encontrada - sofreram modificações/adaptações diante do que se coletou. Registre-se que pesquisas realizadas no campo das ciências sociais e humanas não podem consagrar - a priori - os questionamentos iniciais, sob pena de cometerem equívocos que podem comprometer uma visão mais equânime e ponderada acerca do objeto estudado.

Na primeira etapa, realizou-se levantamento de: documentos dos dez municípios, com foco em leis, decretos, planos, resoluções, atas, programas e projetos e organogramas das secretarias/diretorias de educação; dados populacionais, de condições de vida e de moradia; dados educacionais. Na segunda etapa, foram realizadas entrevistas com os(as) dirigentes responsáveis pelas Secretarias Municipais de Educação (SMEs) - em alguns casos, com a participação de equipes centrais - apoiadas em questionário semiestruturado. 
É preciso assinalar que as informações coletadas em campo por meio das entrevistas não constituíram objeto específico de análise, tendo sido cotejadas com as fontes secundárias, com vistas a ampliar a visão acerca da capacidade institucional dos municípios estudados. Em alguns casos, as falas confirmaram o que se obteve por meio dos dados documentais; em outros, constataram-se divergências em relação a essas fontes. Em outros termos, as falas dos entrevistados subsidiaram a análise dos demais dados, possibilitando identificar com mais acuidade as potencialidades e os limites no que tange à gestão municipal da educação básica.

Os dados foram sistematizados e agregados em torno de cinco categorias de análise, a saber: estrutura e funcionamento do sistema/rede de ensino; gestão de pessoas; gestão pedagógica; financiamento; finalmente, este trabalho focará a quinta categoria - programas e projetos - estruturada com base na análise da realização de convênios, contratos e parcerias com: os governos federal e estadual; outros municípios; o setor privado lucrativo e não lucrativo; universidades; outras secretarias e/ ou órgãos da administração municipal. Foram considerados também os programas e projetos implementados por iniciativa da própria secretaria/diretoria de Educação e de suas equipes.

Destaque-se que, na investigação original, o volume de informações decorrentes das parcerias, programas e projetos existentes nos municípios pesquisados imputou a esta categoria uma maior complexidade. Diante do exposto, dividimos os conteúdos em dois blocos, sendo que o primeiro diz respeito às parcerias realizadas para o desenvolvimento de programas com os seguintes entes federados e entidades: os governos federal e estadual; a iniciativa privada/ONGs; as universidades; outras secretarias/órgãos municipais. Na sequência, apresentam-se programas e projetos realizados por meio de contratos, convênios, parcerias e/ou termos de adesão, nos municípios pesquisados, agrupados da seguinte forma: gestão e planejamento, gestão pedagógica, formação e rede de apoio ${ }^{8}$ às ações educacionais.

Os dez municípios pesquisados realizam 339 programas ou projetos com apoio de diversos parceiros e, também, com recursos próprios, ${ }^{9}$ sendo que a realização de contratos, convênios e parcerias ocorre em maior volume com o governo federal, contabilizando 90 ações de diferentes naturezas. Os programas realizados com recursos das próprias secretarias municipais totalizam 75 ações. Com outras secretarias do governo municipal e com a iniciativa privada, os municípios executam 59 e 57 programas ou projetos, respectivamente. Ainda, registram-se ações desenvolvidas em parceria com o governo estadual (37), com universidades (12) e com outros municípios (2).

Além da expressiva presença do governo federal na execução de programas em parceria com os municípios, destaca-se o conjunto de ações desenvolvidas com 
Contratos, convênios e parcerias na gestão da educação em municípios...

recursos próprios e em parceria com outras secretarias ou setores do governo municipal, que juntos somam 39,5\% de todos os programas. A Tabela 1 registra esses números e os percentuais de participação desses parceiros.

\section{Tabela 1}

Parcerias para o desenvolvimento de Programas na rede municipal, por município e segundo o parceiro, em 2012

\begin{tabular}{|l|c|c|}
\hline \multicolumn{1}{|c|}{ Parceiro } & $\begin{array}{c}\text { Quantidade de } \\
\text { Programas em } \\
\text { desenvolvimento }\end{array}$ & \% \\
\hline Governo Federal & 90 & 26,5 \\
\hline Governo Estadual & 37 & 10,9 \\
\hline Outras Secretarias de Governo & 59 & 17,4 \\
\hline Instituições Privadas e ONGs & 57 & 16,8 \\
\hline Universidades & 12 & 3,5 \\
\hline Desenvolvidos com recursos próprios & 75 & 22,1 \\
\hline Outro município & 2 & 0,6 \\
\hline Sem informação & 7 & 2,1 \\
\hline Total & 339 & $\mathbf{1 0 0 , 0}$ \\
\hline
\end{tabular}

Fonte: Relatório de pesquisa "A capacidade institucional de municípios: uma análise de políticas educacionais em regiões metropolitanas" (MARTINS et al., 2013b).

Um maior detalhamento permite identificar quais são os municípios que mais desenvolvem projetos com recursos próprios e em parceria com as demais secretarias de governo. Destacam-se apenas três municípios aqui denominados de SAT, B e SPN, ${ }^{11}$ dentre os que realizam maior número de programas com recursos municipais. A Tabela 2 registra essas informações.

\section{Tabela 2}

Desenvolvimento de Programas na rede municipal com recursos próprios e com outras secretarias do governo municipal, por município, em 2012.

\begin{tabular}{|c|c|c|c|c|c|}
\hline Município & $\begin{array}{c}\text { Com recursos } \\
\text { próprios da } \\
\text { Educação }\end{array}$ & $\%$ & $\begin{array}{c}\text { Com outras } \\
\text { secretarias } \\
\text { do governo } \\
\text { municipal }\end{array}$ & $\%$ & $\begin{array}{c}\text { Total de programas } \\
\text { realizados com } \\
\text { recursos do próprio } \\
\text { município }\end{array}$ \\
\hline A & 2 & 28,6 & 5 & 71,4 & 7 \\
\hline B & 12 & 50,0 & 12 & 50,0 & 24 \\
\hline C & 2 & 100,0 & 0 & 0,0 & 2 \\
\hline
\end{tabular}




\begin{tabular}{|c|c|c|c|c|c|}
\hline E & 6 & 50,0 & 6 & 50,0 & 12 \\
\hline I & 6 & 66,6 & 3 & 33,3 & 9 \\
\hline NO & 0 & 0,0 & 9 & 100,0 & 9 \\
\hline P & 1 & 25,0 & 3 & 75,0 & 4 \\
\hline SPN & 12 & 66,6 & 6 & 33,3 & 18 \\
\hline SAT & 28 & 80,0 & 7 & 20,0 & 35 \\
\hline SBA & 6 & 42,7 & 8 & 57,1 & 14 \\
\hline Total & 75 & $\mathbf{1 0 0 , 0}$ & $\mathbf{5 9}$ & $\mathbf{1 0 0 , 0}$ & $\mathbf{1 3 4}$ \\
\hline
\end{tabular}

Fonte: Relatório de pesquisa "A capacidade institucional de municípios: uma análise de políticas educacionais em regiões metropolitanas" (MARTINS et al., 2013b).

A possibilidade de realização de projetos com recursos próprios das secretarias de Educação ou em parceria com as demais secretarias do governo municipal está relacionada com o quadro geral das finanças nos municípios. Os programas e projetos realizados por meio de contratos, convênios, parcerias e/ou termos de adesão, nos municípios pesquisados, foram agrupados ainda em torno de quatro subcategorias: Gestão e Planejamento; Gestão Pedagógica; Formação; e Rede de Apoio às Ações Educacionais, distribuídas conforme a Tabela 3.

Tabela 3

Distribuição dos programas desenvolvidos nos municípios

\begin{tabular}{|c|c|c|}
\hline Subcategorias & $\begin{array}{c}\text { Quantidade de } \\
\text { programas em } \\
\text { desenvolvimento }\end{array}$ & \% \\
\hline Gestão e Planejamento & 139 & 41,0 \\
\hline Gestão Pedagógica & 76 & 22,4 \\
\hline Formação & 69 & 8,8 \\
\hline Rede de Apoio & 30 & 7,4 \\
\hline Sem identificação do & 25 & 100,0 \\
\hline Programa
\end{tabular}

Fonte: Relatório de pesquisa "A capacidade institucional de municípios: uma análise de políticas educacionais em regiões metropolitanas" (MARTINS et al., 2013b). 


\section{Questões referentes à gestão e ao planejamento}

Juntos, os municípios pesquisados desenvolvem 139 ações ligadas à gestão e ao planejamento das redes de ensino. Neste item, o principal parceiro dos municípios é o governo federal, com 68 ações, sendo que a maioria delas voltadas às avaliações de larga escala, seguida dos investimentos em infraestrutura, recursos financeiros para as escolas e transporte escolar. Dos dez municípios, nove assinaram o PAR. A Tabela 4 apresenta a natureza dessas ações e os parceiros que apoiam os municípios em sua realização.

\section{Tabela 4}

Programas de "Gestão e Planejamento", por parceiros ${ }^{13}$

\begin{tabular}{|c|c|c|c|c|c|c|c|c|c|}
\hline $\begin{array}{c}\text { Gestão e } \\
\text { Planejamento }\end{array}$ & Federal & Estadual & $\begin{array}{c}\text { Outras } \\
\text { Secs }\end{array}$ & $\begin{array}{l}\text { Privadas/ } \\
\text { ONGs }\end{array}$ & $\begin{array}{l}\text { Univer- } \\
\text { sidade }\end{array}$ & Próprio & $\begin{array}{l}\text { Outro } \\
\text { munic. }\end{array}$ & Existe & Total \\
\hline Alimentação & & 3 & 1 & 1 & & 1 & & 0 & 6 \\
\hline $\begin{array}{l}\text { Ampliação } \\
\text { do acesso }\end{array}$ & 1 & & 1 & 2 & & & & & 4 \\
\hline $\begin{array}{l}\text { Avaliação } \\
\text { docente }\end{array}$ & & & & & & 5 & & & 5 \\
\hline $\begin{array}{l}\text { Avaliações } \\
\text { de larga escala }\end{array}$ & 19 & 7 & & 3 & & 5 & & & 34 \\
\hline $\begin{array}{l}\text { Transferência } \\
\text { de recursos } \\
\text { humanos }\end{array}$ & & 2 & & & & & & & 2 \\
\hline $\begin{array}{l}\text { Educação em } \\
\text { período integral }\end{array}$ & & & & & & 1 & & & 1 \\
\hline Infraestrutura & 11 & 3 & 1 & 2 & & 1 & 1 & & 19 \\
\hline $\begin{array}{l}\text { Manutenção } \\
\text { de prédios } \\
\text { escolares }\end{array}$ & & & & 4 & & & & & 4 \\
\hline $\begin{array}{l}\text { PAR (Plano } \\
\text { de Ações } \\
\text { Articuladas) }\end{array}$ & 9 & & & & & & & & 9 \\
\hline
\end{tabular}




\begin{tabular}{|c|c|c|c|c|c|c|c|c|c|}
\hline $\begin{array}{l}\text { Participação da } \\
\text { comunidade }\end{array}$ & 1 & & 1 & & & 1 & & & 3 \\
\hline $\begin{array}{l}\text { PDE (Plano } \\
\text { de Desenvol- } \\
\text { vimento da } \\
\text { Educação) }\end{array}$ & 4 & & & & & & & & 4 \\
\hline $\begin{array}{l}\text { Plano de } \\
\text { carreira }\end{array}$ & & & & 2 & & 1 & & 7 & 10 \\
\hline $\begin{array}{l}\text { PNAE } \\
\text { (Programa } \\
\text { Nacional de } \\
\text { Alimentação } \\
\text { Escolar) }\end{array}$ & 3 & & & & & & & & 3 \\
\hline $\begin{array}{l}\text { PNLD } \\
\text { (Programa } \\
\text { Nacional do } \\
\text { Livro Didático) }\end{array}$ & 9 & & & & & & & & 9 \\
\hline Premiações & & & & & & 2 & & & 2 \\
\hline $\begin{array}{l}\text { Recursos } \\
\text { financeiros } \\
\text { para escolas }\end{array}$ & 8 & & & & & 4 & & & 12 \\
\hline $\begin{array}{l}\text { Sistema } \\
\text { de gestão } \\
\text { informatizado }\end{array}$ & & & & & & 1 & & & 1 \\
\hline Transporte & 4 & 2 & 1 & 3 & & & & & 10 \\
\hline $\begin{array}{l}\text { Uniforme } \\
\text { escolar }\end{array}$ & 0 & & & 2 & & & & & 2 \\
\hline TOTAL & 68 & 17 & 30 & 19 & 0 & 22 & 1 & 7 & 139 \\
\hline
\end{tabular}

Fonte: Relatório de pesquisa "A capacidade institucional de municípios: uma análise de políticas educacionais em regiões metropolitanas" (MARTINS et al., 2013b).

Verifica-se a predominância do governo federal no relacionamento com os municípios, levando-nos a afirmar que os elementos que compõem o regime de colaboração no Brasil configuram um desenho político-institucional ainda bastante vulnerável para a esfera municipal. É interessante observar que, no caso paulista, a 
Contratos, convênios e parcerias na gestão da educação em municípios...

descentralização - pela via da municipalização do ensino - não consolidou, necessariamente, a predominância da esfera estadual no relacionamento com as municipalidades.

\section{Questões referentes à gestão pedagógica}

Enquanto as ações de gestão e planejamento têm como parceiro privilegiado o governo federal, as ações organizadas em torno da subcategoria “Gestão Pedagógica" ocorrem na maioria das vezes em parceria com a iniciativa privada, como se verifica na Tabela 5. Verifica-se, além dessa modalidade de entrada do setor privado na gestão do ensino público, a presença das assessorias e consultorias. Os programas que contemplam a Gestão Pedagógica priorizam o enriquecimento curricular e o material didático, como se pode ver na Tabela 5 .

\section{Tabela 5}

Programas de "Gestão Pedagógica", por parceria

\begin{tabular}{|c|c|c|c|c|c|c|c|c|}
\hline $\begin{array}{c}\text { GESTÃO } \\
\text { PEDAGÓGICA }\end{array}$ & Federal & Estadual & $\begin{array}{c}\text { Outras } \\
\text { Secs }\end{array}$ & $\begin{array}{l}\text { Privadas/ } \\
\text { ONGs }\end{array}$ & $\begin{array}{l}\text { Univer- } \\
\text { sidade }\end{array}$ & Próprio & $\begin{array}{c}\text { Outro } \\
\text { município }\end{array}$ & Total \\
\hline $\begin{array}{l}\text { Apoio para aprendi- } \\
\text { zagem/reforço escolar }\end{array}$ & & & & & & 2 & & 2 \\
\hline $\begin{array}{l}\text { Educação de Jovens e } \\
\text { Adultos }\end{array}$ & & & & 2 & & 1 & & 3 \\
\hline Educação Inclusiva & 2 & & 1 & 1 & & 2 & & 6 \\
\hline Educação Profissional & 1 & 1 & 1 & 2 & & & & 5 \\
\hline $\begin{array}{l}\text { Enriquecimento } \\
\text { curricular (meio } \\
\text { ambiente, educação } \\
\text { financeira, temas } \\
\text { transversais, entre } \\
\text { outros) }\end{array}$ & 1 & 3 & 5 & 9 & & 9 & 1 & 28 \\
\hline $\begin{array}{l}\text { Material didático } \\
\text { curricular }\end{array}$ & 9 & 7 & 5 & 6 & & 1 & & 28 \\
\hline PNBE & 1 & & & & & & & 1 \\
\hline $\begin{array}{l}\text { Tecnologia } \\
\text { educacional }\end{array}$ & & 1 & & 2 & & & & 3 \\
\hline TOTAL & 14 & 12 & 12 & 22 & 0 & 15 & 1 & 76 \\
\hline
\end{tabular}

Fonte: Relatório de pesquisa "A capacidade institucional de municípios: uma análise de políticas educacionais em regiões metropolitanas" (MARTINS et al., 2013b). 


\section{Questões referentes à formação}

Foram registradas 69 ações de formação ou desenvolvimento profissional, a maioria delas voltada para os professores e executada pelos próprios municípios. $\mathrm{O}$ agrupamento dos conteúdos relaciona-se a programas de desenvolvimento profissional para gestores, professores, funcionários e programas de formação para conselheiros e pais. A seguir, apresentam-se as tabelas que permitem identificar as ações formativas para cada um dos segmentos da gestão educacional e os parceiros dos municípios na execução. A oferta de formação para o desenvolvimento profissional de gestores se concentrou nas iniciativas realizadas com recursos humanos e financeiros dos próprios municípios, conforme a Tabela 6.

\section{Tabela 6}

Programas de “Desenvolvimento Profissional - Gestores", por parceiros ${ }^{14}$

\begin{tabular}{|l|c|c|c|c|c|c|c|}
\hline $\begin{array}{c}\text { Ações de formação } \\
\text { continuada para } \\
\text { gestores }\end{array}$ & Federal & Estadual & $\begin{array}{c}\text { Outras } \\
\text { Secs }\end{array}$ & Próprio & $\begin{array}{c}\text { Universi- } \\
\text { dade }\end{array}$ & $\begin{array}{c}\text { Privadas/ } \\
\text { ONGs }\end{array}$ & Total \\
\hline Curso de extensão & 2 & 1 & & & 1 & & 1 \\
\hline $\begin{array}{l}\text { Formação } \\
\text { continuada de } \\
20 \text { a 120 horas }\end{array}$ & 2 & 1 & 0 & 6 & 2 & 2 & 12 \\
\hline TOTAL & "A & 1 & 6 & 1 & 2 & 12 \\
\hline
\end{tabular}

Fonte: Relatório de pesquisa "A capacidade institucional de municípios: uma análise de políticas educacionais em regiões metropolitanas" (MARTINS et al., 2013b).

Embora a oferta de formação para professores se concentre nas iniciativas realizadas com recursos humanos e financeiros dos próprios municípios, verifica-se, em quantidade relativamente expressiva, as ações desenvolvidas com o apoio do governo federal, com universidades e instituições privadas, conforme registrado na Tabela 7, na próxima página.

Funcionários foram contemplados exclusivamente por iniciativas realizadas com recursos humanos e financeiros dos próprios municípios, conforme registra a Tabela 8, na próxima página.

Os conselheiros municipais da Educação foram contemplados majoritariamente pelo Programa Pró-Conselho, do governo federal, conforme se verifica na Tabela 9, na página seguinte. 
Contratos, convênios e parcerias na gestão da educação em municípios...

Tabela 7

Programas de “Desenvolvimento Profissional - Professores", por parceiros

\begin{tabular}{|c|c|c|c|c|c|c|c|c|}
\hline $\begin{array}{c}\text { Ações de } \\
\text { formação } \\
\text { continuada para } \\
\text { professores }\end{array}$ & Fed & Est & $\begin{array}{l}\text { Outras } \\
\text { Secs }\end{array}$ & Próprio & $\begin{array}{l}\text { Universi- } \\
\text { dade }\end{array}$ & $\begin{array}{l}\text { Privadas/ } \\
\text { ONGs }\end{array}$ & $\begin{array}{l}\text { Outro } \\
\text { município }\end{array}$ & Total \\
\hline $\begin{array}{l}\text { Curso de } \\
\text { extensão }\end{array}$ & & & & & 4 & & & 4 \\
\hline $\begin{array}{l}\text { Aprimoramento } \\
\text { curricular }\end{array}$ & & 1 & & 1 & & & 1 & 3 \\
\hline $\begin{array}{l}\text { Formação para } \\
\text { atuar em projetos } \\
\text { financiados por } \\
\text { ONGs e empresas } \\
\text { privadas }\end{array}$ & & & & & & 2 & & 2 \\
\hline $\begin{array}{l}\text { Curso de } \\
\text { formaçãao } \\
\text { continuada de } 20 \\
\text { a } 120 \text { horas }\end{array}$ & 7 & 1 & & 12 & 3 & 6 & & 29 \\
\hline $\begin{array}{l}\text { Licenciatura / } \\
\text { Parfor }\end{array}$ & 2 & & & & 1 & & & 3 \\
\hline TOTAL & 9 & 2 & 0 & 13 & 8 & 8 & 1 & 41 \\
\hline
\end{tabular}

Fonte: Relatório de pesquisa "A capacidade institucional de municípios: uma análise de políticas educacionais em regiões metropolitanas" (MARTINS et al., 2013b).

Tabela 8

Programas de “Desenvolvimento Profissional - Funcionários", por parceiros

\begin{tabular}{|c|c|c|c|c|c|c|c|}
\hline $\begin{array}{c}\text { Ações de } \\
\text { formação } \\
\text { continuada para } \\
\text { funcionários }\end{array}$ & Federal & Estadual & $\begin{array}{c}\text { Outras } \\
\text { Secs }\end{array}$ & Próprio & $\begin{array}{c}\text { Universi- } \\
\text { dades }\end{array}$ & $\begin{array}{c}\text { Privadas/ } \\
\text { ONGs }\end{array}$ & Total \\
\hline $\begin{array}{l}\text { Curso de } \\
\text { formação } \\
\text { continuada de } 20 \\
\text { a } 120 \text { horas }\end{array}$ & & & & 7 & & & 7 \\
\hline TOTAL & 0 & 0 & 0 & 7 & 0 & 0 & 7 \\
\hline
\end{tabular}

Fonte: Relatório de pesquisa "A capacidade institucional de municípios: uma análise de políticas educacionais em regiões metropolitanas" (MARTINS et al., 2013). 
Tabela 9

Programas de "Formação - Conselheiros", por parceiros

\begin{tabular}{|c|c|c|c|c|c|c|c|}
\hline $\begin{array}{l}\text { Ações de formação } \\
\text { continuada para } \\
\text { conselheiros }\end{array}$ & Federal & Estadual & $\begin{array}{l}\text { Outras } \\
\text { Secs }\end{array}$ & Próprio & $\begin{array}{l}\text { Universi- } \\
\text { dades }\end{array}$ & $\begin{array}{c}\text { Privadas/ } \\
\text { ONGs }\end{array}$ & Total \\
\hline Curso de extensão & 2 & & & & & & 2 \\
\hline $\begin{array}{l}\text { Curso de formação } \\
\text { continuada de } 20 \text { a } \\
120 \text { horas }\end{array}$ & 4 & & & 1 & & & 5 \\
\hline TOTAL & 6 & 0 & 0 & 1 & 0 & 0 & 7 \\
\hline
\end{tabular}

Fonte: Relatório de pesquisa "A capacidade institucional de municípios: uma análise de políticas educacionais em regiões metropolitanas" (MARTINS et al., 2013b).

Além dessas ações de formação, registrou-se apenas uma iniciativa municipal de formação para pais de alunos, conforme informações coletadas em campo.

\section{Questões referentes à rede de apoio às ações educacionais}

Registraram-se, ainda, trinta programas ou projetos desenvolvidos em torno de tema candente atualmente na área da educação: construção ou manutenção de rede de apoio às ações educacionais. Estes, em sua maioria, são realizados com a parceria de outras secretarias de governo dos próprios municípios. Os programas de Rede de Apoio às Ações Educacionais concentram-se na área da saúde, seguida da área de proteção e segurança (ronda escolar e conselho tutelar), conforme se registra na Tabela 10.

\section{Tabela 10}

Programas de "Rede de Apoio às Ações Educacionais", por parceria

\begin{tabular}{|l|l|c|c|c|c|c|c|}
\hline REDE DE PROTEÇÃo & Federal & Estadual & $\begin{array}{c}\text { Outras } \\
\text { Secs }\end{array}$ & $\begin{array}{c}\text { Privadas/ } \\
\text { ONGs }\end{array}$ & $\begin{array}{c}\text { Universi- } \\
\text { dades }\end{array}$ & Próprio & Total \\
\hline $\begin{array}{l}\text { Ações de proteção } \\
\text { (segurança, conselho } \\
\text { tutelar, ronda escolar) }\end{array}$ & 3 & 2 & 1 & & 1 & 7 \\
\hline $\begin{array}{l}\text { Capacitação e inserção } \\
\text { de jovens no mercado de } \\
\text { trabalho }\end{array}$ & & & 1 & & & & 1 \\
\hline
\end{tabular}




\begin{tabular}{|c|c|c|c|c|c|c|c|}
\hline $\begin{array}{l}\text { Complementação } \\
\text { de renda (concessão } \\
\text { de bolsa) }\end{array}$ & & & 1 & & & & 1 \\
\hline Conselho Tutelar & & 1 & & & & & 1 \\
\hline Esportes & & & 3 & 2 & & & 5 \\
\hline Ministério Público & & 2 & & & & & 2 \\
\hline Saúde & & & 11 & 1 & 1 & & 13 \\
\hline TOTAL & 0 & 6 & 17 & 5 & 1 & 1 & 30 \\
\hline
\end{tabular}

Fonte: Relatório de pesquisa "A capacidade institucional de municípios: uma análise de políticas educacionais em regiões metropolitanas" (MARTINS et al., 2013b).

\section{Considerações finais}

A esfera municipal logrou centralidade desde a promulgação da Constituição da República Federativa do Brasil de 1988 (BRASIL, 1988), ${ }_{1}^{15}$ quando se estabeleceram princípios descentralizadores e municipalistas. A referida Constituição preconizou a transferência de recursos fiscais para estados e municípios, definiu a competência dos municípios nas áreas de educação infantil, fundamental e na saúde (cooperação técnica e financeira do Estado e da União), conferiu centralidade das câmaras municipais em processos decisórios e configurou estratégias indutoras de criação dos conselhos locais.

A literatura da área indica conflitos de opinião em relação ao tema das possibilidades e limites de municípios brasileiros assumirem de forma equânime políticas públicas sociais, pois, de uma parte, há os que defendem o fortalecimento do poder local como mecanismo democrático exercido em pequena escala (SANTOS; AVRITZER, 2002). De outra parte, há aqueles que apontam problemas estruturais na capacidade política e institucional de municípios no que tange: às questões financeiras; às dificuldades de organização e estrutura do aparato burocrático; à ausência de quadros administrativos bem preparados e qualificados para enfrentar os desafios de atendimento no setor social; à prevalência de práticas clientelísticas em muitas municipalidades (MARTINS, 2005).

Registre-se ainda que há divergência doutrinária sobre a "questão dos municípios participarem, ou não, da repartição das competências concorrentes, por não estarem previstos expressamente no artigo 24 da Constituição de 1988 como titulares dos poderes elencados, ao lado da União e estados" (BERCOVICI, 2009, p. 4). Entretanto, há uma contradição, pois, apesar de não constarem expressamente 
no artigo 24, não há clareza sobre o fato de os municípios terem sido excluídos ou não da repartição de competências concorrentes, considerando-se o disposto no artigo 30, II, da Constituição, que dá competência aos municípios para legislarem de maneira suplementar no que lhes couber.

O autor aponta a necessidade, ainda, de se definir o que se entende por normas gerais, previstas nos $\S \S^{\circ}{ }^{\circ}, 2^{\circ}, 3^{\circ}$ e $4^{\circ}$ do artigo 24 da Constituição de 1988. Acrescenta que, na repartição de competências, a cooperação se revela nas chamadas competências comuns, consagradas no artigo 23 da Constituição de 1988, por meio das quais todos os entes da Federação devem colaborar para a execução das tarefas determinadas pela Constituição. Bercovici (op. cit.) sublinha que, como a lei complementar prevista no parágrafo único do artigo 23 da Constituição de 1988 não foi elaborada, não há no sistema federal brasileiro um regime jurídico expresso de instituição das tarefas comunitárias - tais como as existentes na Alemanha -, embora haja uma estrutura similar introduzida a partir da nova redação do artigo 241 da Constituição de 1988 e a aprovação da lei dos consórcios públicos.

Esse processo - de modo geral denominado de federalismo híbrido - vem gerando inúmeros problemas: efetivamente, os municípios logram recursos de redistribuição tributária com a contrapartida de encargos; as esferas subnacionais de governo aumentaram sua capacidade financeira e assumiram responsabilidades de maneira descoordenada e diferenciada entre as regiões; o sistema presidencialista multipartidário nunca tem maioria, o que tem provocado coalizações fisiológicas ou baseadas em negociação pontual (MARTINS, 2005).

Os dez municípios examinados apresentam diferentes portes e condições político-sociais. Entretanto, estão localizados em regiões metropolitanas privilegiadas do ponto de vista de desenvolvimento econômico. Realizam expressivo número de programas ou projetos com apoio de diversos parceiros e, também, com recursos próprios (339). Porém, a realização de contratos, convênios e parcerias ocorre em maior volume com o governo federal, contabilizando noventa ações de diferentes naturezas. Destaque deve ser dado aos programas realizados com recursos das próprias secretarias municipais que totalizam 75 ações. A implementação de programas ou projetos com apoio de outras secretarias do governo municipal e com a iniciativa privada também revela um número de ações bastante expressivo: 59 e 57 programas ou projetos, respectivamente. Em volume muito menor são registradas ações desenvolvidas em parceria com o governo estadual (37), com universidades (12) e com outros municípios da mesma região (2).

Em outros termos, os dados deste estudo indicam, efetivamente, que prevalece a sobreposição de programas, projetos e medidas induzidas pela esfera federal, com forte presença do setor privado lucrativo e não lucrativo na implementação de ações referentes, principalmente, às ações de formação continuada e/ou de "enriquecimento 
Contratos, convênios e parcerias na gestão da educação em municípios...

curricular", embora tenha sido possível constatar a presença expressiva de ações implementadas por iniciativas das próprias secretarias/diretorias municipais de Educação. Registre-se que a forte presença dos programas federais, no campo educacional, em parcerias e convênios com os municípios, foi igualmente detectada em pesquisa realizada por Azevedo e Santos (2012) em 14 municípios da Região Metropolitana do Recife.

É preciso destacar, contudo, que a preocupação do governo federal em ampliar as relações com os municípios não se restringe ao campo educacional e passou a fazer parte da agenda do governo federal como estratégia de abordagem direta dos entes federados. Essa questão - ponto crucial nas relações intergovernamentais - fez com que o governo federal adotasse medidas tais como a criação de uma Subchefia de Assuntos Federativos (SAF) - primeiro subordinada à Casa Civil (CC) e, posteriormente, à Secretaria de Relações Institucionais (SRI), ambos órgãos da Presidência da República com status de Ministério. A SAF tornou-se locus de articulação - política e programática - da esfera federal com os municípios, atuando como secretaria executiva do Comitê de Articulação Federativa (CAF), formalizado por meio do Decreto n. 6.181, de 3 de agosto de 2007.

O CAF promove a articulação de estratégias e a implementação de ações coordenadas e cooperativas entre as três esferas de governo, para atendimento das demandas da sociedade e aprimoramento das relações federativas, contando com a participação de vinte órgãos do governo federal e com a representação de três entidades municipalistas brasileiras: a Associação Brasileira de Municípios (ABM), a Frente Nacional de Prefeitos (FNP) e a Confederação Nacional dos Municípios (CNM).

Conforme demonstram os dados deste estudo, a esfera federal consolidou suas estratégias direcionadas aos municípios, com a preocupação de estabelecer vínculos institucionais formalizados do ponto de vista legal, normativo e financeiro. Assim, com vistas à efetiva integração das políticas federativas, o próprio CAF instituiu um Grupo de Trabalho para o Fortalecimento Institucional e Qualificação da Gestão dos Municípios, em 2007, para estabelecer horizontes e conceitos comuns em torno da capacidade de gestão municipal, "diminuindo" as distâncias (físicas e simbólicas) entre a esfera federal e os entes municipais, pois, de acordo com o CAF, esta instância carece, até o presente momento, de assistência para capacitação no que diz respeito ao aprimoramento administrativo e tecnológico (incluindo as TICs). Na mesma direção, a fragilidade institucional da maior parte dos municípios brasileiros tem sido apontada em documentos oficias e fóruns de debates preocupados em examinar estruturas administrativas e a capacidade de gestão de programas e projetos. ${ }^{16}$

Entretanto, os novos arranjos político-institucionais, ${ }^{17}$ a redistribuição de competências entre as esferas de governo, a transferência de funções do setor público para 
o setor privado lucrativo ou não lucrativo, com base na instauração de parcerias e convênios, têm configurado formas bastante complexas e multifacetadas na gestão da educação básica municipal. Senão, vejamos.

Como foi dito anteriormente, partiu-se do pressuposto de que, após a Constituição de 1988, e sobretudo no estado de São Paulo, após a consolidação do processo de municipalização, estes entes federados poderiam ter construído dinâmicas de planejamento e gestão das políticas públicas que atendessem de maneira mais equânime a educação básica. ${ }^{18}$

Os dados revelam que, dos dez municípios estudados, cinco apresentam baixa institucionalização e rotinização de diretrizes, programas e projetos - quer sejam realizados por meio de contratos, convênios e parcerias com as esferas federal e estadual, quer sejam realizados com o setor privado lucrativo e não lucrativo. Implementam ações (pontuais) em parceria com empresas privadas no que diz respeito a atividades curriculares, sobretudo na forma de oficinas e/ou palestras isoladas, apontando nomes de consultores/especialistas, embora lancem mão, simultaneamente, de materiais oficiais do MEC.

A presença expressiva da iniciativa privada na gestão pedagógica das redes municipais de ensino já havia sido relatada em estudo de Adrião et al. (2009, p. 806), que identificou a compra, por parcela considerável dos municípios paulistas, de "sistemas de ensino". De acordo com as autoras, um "levantamento preliminar junto ao total dos municípios paulistas indicou que, no período de 1994 a 2006, dos 645 municípios, 161 informaram adotar ou já ter adquirido, neste período, 'sistema apostilado' para a educação infantil e ensino fundamental [...]”. Em 2007, 157 destes municípios ainda mantinham contratos com as empresas.

Entretanto, foi possível verificar forte presença do governo federal em todos eles, no que diz respeito às ações previstas para capacitação e assistência técnica com vistas a fortalecer principalmente as áreas de planejamento, administração e finanças. Observou-se ainda, nos dez municípios, tendência à ampliação de implementação de ações na gestão de recursos humanos, por meio da adequação da normatização/legislação local às normas vigentes em âmbito federal, no que diz respeito, sobretudo, à estruturação de Planos de Carreira.

Chama atenção, ainda, a instauração de processos e instrumentos de interlocução com setores relacionados à rede de proteção e apoio, seja por meio dos conselhos tutelares e órgãos de segurança do estado de São Paulo, ou em atividades integradas com demais secretarias dos próprios municípios. Como foi dito anteriormente, com relação à institucionalização de entidades administrativas metropolitanas, embora tenha sido constatada a existência de agências de desenvolvimento, não há ações integradas realizadas em âmbito regional no campo da educação. 
Contratos, convênios e parcerias na gestão da educação em municípios...

Tendo em vista os achados do estudo, no que diz respeito ao volume de convênios, programas, projetos e termos de adesão com o governo federal, aventou-se a possibilidade de que isso pudesse ocorrer em função da predominância de interesse/ negociações decorrentes das coligações partidárias que elegeram prefeitos, governador e presidente, a partir dos anos 2000.

Assim, a investigação original buscou analisar as possíveis associações entre a presença de programas federais/estaduais nos municípios estudados e os partidos que compuseram as coligações que elegeram os prefeitos para os mandatos de 2001/2004, 2005/2007 e 2009/2012, bem como aquelas que elegeram os governadores do estado de São Paulo e o/a presidente (a) da República para os mandatos 2003/2006, 2007/2010 e 2011/2014. Com base nessa análise, constatou-se que não há associação direta, ao menos nesses dez municípios, entre as coligações que elegeram os prefeitos e os programas/projetos assinados com a esfera federal - preponderantemente - e estadual, em menor volume.

Três dos municípios estudados implementaram ações por iniciativa própria, tomando por base o (re)conhecimento da realidade local, o que indica tendência em atender demandas específicas da população usuária da escola pública, embora lancem mão também de diretrizes, programas e projetos elaborados no âmbito das esferas federal e estadual. Nos demais municípios, as iniciativas registradas de convênios, contratos e parcerias realizados em conjunto com o governo federal, bem como a contratação de "assessorias privadas externas", não expressam exatamente as especificidades das localidades, no que diz respeito, sobretudo, às questões pedagógicas que envolvem ações de enriquecimento curricular, formação continuada e processos avaliativos.

Os dados apontam que ainda há um caminho a percorrer para que os municípios possam planejar, administrar e avaliar, de forma mais estruturada, programas e projetos com vistas a efetivar uma gestão equânime da educação, implementada com autonomia local, constituída por metas registradas em escopo legal e documentos orientadores e normativos que expressem as necessidades das redes/sistemas de ensino municipais.

Por fim, retomando a discussão realizada inicialmente, problemas que afetam municípios localizados em regiões metropolitanas poderiam ser minimizados se houvesse integração entre diferentes setores e esferas governamentais, por exemplo, se fossem potencializadas (e efetivadas) as funções das agências metropolitanas para viabilizar a intersetorialidade e as articulações intergovernamentais, tendo em vista serem vinculadas aos governos estaduais, respondendo, contudo, a diretrizes vindas do governo federal.

Entretanto, com base nos dados obtidos neste estudo, isso não se confirma na área da educação. De acordo com a literatura examinada e dados obtidos em campo, 
a educação não tem sido objeto de preocupação nesses tipos de arranjos metropolitanos, pois o foco, nessas regiões, recai sobre a necessidade de integrar a extensão de redes de água e esgoto, bem como de solucionar questões de moradia, de recolhimento de lixo, de transporte e de saúde. No caso da educação, as parcerias, contratos e convênios são realizados pelos municípios, prioritariamente, com as esferas federal e estadual, além do setor privado lucrativo e não lucrativo.

\section{Notas}

1. A pesquisa intitulada "A capacidade institucional de municípios: uma análise de políticas educacionais em regiões metropolitanas" foi financiada pela Fundação Carlos Chagas (FCC) e pela Fundação de Amparo à Pesquisa de São Paulo (Fapesp). Do estudo participaram Gláucia Novaes, pesquisadora da FCC, e as bolsistas Jessica Munhoz Araújo, Cláudia Oliveira Pimenta e Fabiana Fernandes. Foram consultoras da pesquisa Joana Buarque Gusmão e Valéria Virgínia Lopes. Como pesquisadores associados participaram Cleiton de Oliveira e Pedro Ganzeli. O estudo-piloto foi realizado em dez municípios localizados nas três regiões metropolitanas de São Paulo, com vistas a construir indicadores de gestão da educação municipal.

2. Ver a discussão realizada por Souza $(2003 ; 2006)$ sobre os teóricos precursores no campo das políticas públicas.

3. Ver a discussão realizada por Martins (2010).

4. A literatura sobre regiões metropolitanas foi levantada por Joana Buarque Gusmão, consultora da Fundação Carlos Chagas, sistematizada e analisada no âmbito da pesquisa "A capacidade institucional de municípios: uma análise de políticas educacionais em regiões metropolitanas", financiada pela FCC e pela Fapesp, dando origem a outro estudo em torno das três regiões metropolitanas do estado de São Paulo. Para este artigo, apenas lançamos mão de algumas noções discutidas no referido levantamento, tendo em vista não ser o foco deste trabalho. Sobre isso, ver Martins et al. (2013a).

5. Segundo texto disponível na internet, na página da Coordenação da Região Metropolitana de Curitiba, vinculada à Secretaria do Desenvolvimento Urbano do Estado do Paraná. Disponível em: <http://www.comec.pr.gov.br/modules/conteudo/conteudo.php?conteudo=28>. Acesso em: 9 maio 2012.

6. Disponível em: <http://www.comec.pr.gov.br/modules/conteudo/conteudo.php?conteudo=28>. Acesso em: 9 maio 2012.

7. Lei Complementar n. 14, à qual se seguiu a Constituição de 1967.

8. Foram agrupados no item "rede de apoio" os programas que não estão diretamente relacionados ao ensino ou sua gestão, mas que contribuem para sua realização, tais como os programas de saúde e proteção à criança e ao adolescente.

9. Denomina-se "recursos próprios" aqueles que estão disponíveis na rede municipal, advêm do erário municipal, tanto no que diz respeito aos recursos financeiros, quanto no que se refere ao quadro de profissionais.

10. Sabe-se da existência dos programas, mas não se tem informações sobre os eventuais parceiros na execução.

11. Os nomes estão na forma de siglas por motivos éticos.

12. Neste caso, sabe-se da existência de Programas, mas não se tem informações sobre seus conteúdos.

13. Na última coluna estão registradas informações dos municípios que indicam ter planos de carreira elaborados e/ ou em implementação na forma de parcerias, sem explicitar de que forma e quem são os parceiros. 
Contratos, convênios e parcerias na gestão da educação em municípios...

14. Desenvolvimento profissional para secretários, diretores, coordenadores e orientadores.

15. Disponível em: <http://www.planalto.gov.br/ccivil_03/constituicao/constituicao.htm>. Acesso em: 15 set. 2010.

16. Conforme aponta Rodrigo Lofrano (2010), no Painel "Articulação federativa na prestação de serviços sociais", realizado no III Congresso de Gestão Pública. Ver: Mecanismos de desenvolvimento institucional: programas de apoio aos municípios. Disponível em: <www.repositorio.seap.pr.gov.br.arquivos/ File/Material\%20CONSAD/paineisIIIcongressoconsad/painel 51/mecanismos de desenvolvimento institucional.pdf.> Acesso em: 2 ago 2011.

17. Ver, a título de exemplo, o Programa do Ministério do Planejamento "Brasil Municípios", cujo principal eixo consiste em prestar assistência técnica, visando o "reforço da capacidade de gestão dos municípios por meio da oferta de consultoria especializada para a realização de diagnóstico organizacional, estruturação e modernização da gestão. Promove ações nas áreas de planejamento governamental, gestão por resultados, elaboração e gestão de projetos que contribuam para o desenvolvimento, a inclusão social e a redução da pobreza". Disponível em: <http://www.projetobrasilmunicipios.gov.br/content/eixo-de-assist\%C3\%AAncia-t\%C3\%A9cnica>. Acesso em: 12 abr. 2011.

18. É preciso esclarecer que a pesquisa original não estabeleceu juízo de valor para classificar os municípios examinados, tendo sido construídos indicadores qualitativos de gestão, considerando que componentes organizacionais não são os mesmos para todos os municípios.

\section{Referências}

ADRIÃO, T. et al. Uma modalidade peculiar de privatização da educação pública: a aquisição de 'sistemas de ensino' por municípios paulistas. Educação \& Sociedade, Campinas, v. 30, n. 108, p. 799-818, out. 2009.

AZEVEDO, J.M.L.; SANTOS, A.L.F. Influências do poder central no planejamento da educação dos municípios da Região Metropolitana do Recife. Educação \& Sociedade, Campinas, v. 33, n. 119, p. 551-573, abr.-jun. 2012.

BERCOVICI, G. O Federalismo no Brasil e os limites da competência legislativa e administrativa: memórias da pesquisa. In: Revista Jurídica. Brasília, DF: Presidência da República; Casa Civil, 2009.

BRASIL. Ministério do Planejamento. Melhoria da gestão pública por meio da definição de um guia referencial para a medição do desempenho da gestão e controle para o gerenciamento dos indicadores de eficiência, eficácia e de resultados do programa nacional de gestão pública e desburocratização. Produtos 1 e 4. Brasília, DF: Ministério do Planejamento, 2009. Disponível em: <http://www.planalto.gov.br/ccivil_03/constituicao/ constitui\%C3\%A7ao.htm>. Acesso em: 15 set. 2010.

CRUZ, M..C. M. T.; MONTORO, F.A.F.; BIO, S.R. Reflexões sobre a capacidade de gestão paulista: análise das gestões financeira, de capital e infraestrutura, de pessoas e de tecnologia da informação. In: CONGRESSO CONSAD DE GESTÃO PÚBLICA, 4., Brasília, DF, 25 a 17 de maio de 2001. 
FREITAS, R. Regiões metropolitanas: uma abordagem conceitual. Humanae, v. 1, n. 3, p. 44-53, dez. 2009. Disponível em: <http://www.esuda.com.br/revista/final/artigos/ h-3_3Ruskin.pdf>. Acesso em: 9 maio 2012.

FREY, K. Políticas públicas: um debate conceitual e reflexões referentes à prática da análise de políticas públicas. Revista Planejamento e Políticas Públicas, Brasília, DF, n. 21, p. 212-279, jun. 2000. Disponível em: <http://desafios2.ipea.gov.br/ppp/index.php/ PPP/article/viewFile/89/158>. Acesso em: 12 out. 2010.

GOUVÊA, R.G. Diretrizes para a gestão metropolitana no Brasil. Eure, Santiago do Chile, v. 35, n. 104, p. 47-76, abr. 2009.

GOVERNO DO ESTADO DO PARANÁ. Secretaria do Desenvolvimento Urbano. Coordenação da Região Metropolitana de Curitiba. Histórico institucional. Disponível em: <http://www.comec.pr.gov.br/modules/conteudo/conteudo.php?conteudo=28>. Acesso em: 9 maio 2012.

LIPPI, M.F. A estratégia de articulação intergovernamental na implantação de políticas públicas metropolitanas: construindo um conceito e evidenciando a aplicação prática. In: CONGRESSO CONSAD DE GESTÃO PÚBLICA, 2. Anais... Brasília, DF: Consad, 2009. Disponível em: <http://www.consad.org.br/sites/1500/1504/00000126. pdf>. Acesso em: 10 maio 2012.

LOFRANO, R. Mecanismos de desenvolvimento institucional: programas de apoio aos municípios. In: CONGRESSO CONSAD DE GESTÃO PÚBLICA, 3., Brasília, DF, 14 a 17 de março de 2010. Disponível em: <http://www.consad.org.br/sites/1500/ 1504/00002003.pdf>. Acesso em: 18 jul. 2010.

MARICATO, E. Metrópoles desgovernadas. Estudos avançados, São Paulo, v. 25, n. 71, jan./abr. 2011.

MARTINS, A.M. A municipalização do ensino. 1. ed. Santos: Leopoldianum, 2005.

MARTINS, A.M. Estudos em políticas educacionais. In: MARTINS, Â.M.; WERLE, F.O.C. (Org.). Políticas educacionais: elementos para reflexão. Porto Alegre: Capes/ Redes Editora, 2010. p. 21-49.

MARTINS A.M. et al. Políticas educacionais em regiões metropolitanas no estado de São Paulo: desafios no atendimento da educação básica. São Paulo: Fundação Carlos Chagas/Fapesp, 2013a. (Relatório Final).

MARTINS, A.M. et al. A capacidade institucional de municípios: uma análise de políticas educacionais em regiões metropolitanas. São Paulo: Fundação Carlos Chagas/ Fapesp, 2013b. (Relatório Final de Pesquisa). 
PERES, R.G; ZIMMERMANN, G. Gestão e planejamento de cidades e políticas sociais: gestão metropolitana - possibilidades e desafios. In: BAENINGER, R. (Org.). População e cidades: subsídios para o planejamento e para as políticas sociais. Campinas: Nepo/Unicamp; Brasília, DF: Unfpa, 2010. p. 154-161.

SANTOS, B.S.; AVRITZER, L. Introdução: para ampliar o cânone democrático. In: SANTOS, B.S. (Org.). Democratizar a democracia - os caminhos da democracia participativa. Rio de Janeiro: Civilização Brasileira, 2002. p. 39-82.

SOUZA, C. "Estado do Campo" da pesquisa em políticas públicas no Brasil. Revista Brasileira de Ciências Sociais, v. 18, n. 51, p. 69-79, fev. 2003.

SOUZA, C. Políticas públicas: uma revisão da literatura. Revista Sociologia, Porto Alegre, v. 8, n. 16, p. 20-45, jul./dez. 2006. Disponível em: <http://www.scielo.br/pdf/ soc/n16/a03n16.pdf>. Acesso em: 21 set. 2011.

\section{Sites consultados}

A AVALIAÇÃO do Desenvolvimento Socioeconómico - Manual Técnico I. Disponível em: <www.observatorio.pt/download.php?id=180>. Acesso em: 30 ago. 2011.

BRASIL. Constituição da República Federativa do Brasil. Brasília, DF: Presidência da República; Casa Civil, 1988. Disponível em: <http://www.planalto.gov.br/ccivil_03/ constituicao/constituicao.htm>. Acesso em: 15 set. 2010.

PORTAL DOMEC. Disponívelem: <http://www.portal.mec.gov.br/index.php?option= com_pea>. Acesso em: 25 jul. 2011.

PROJETO BRASIL. Disponível em: <http://www.projetobrasilmunicipios.gov.br/ content/eixo-de-assist\%C3\%AAnciat\%C3\%A9cnica>. Acesso em: 12 abr. 2011.

Recebido em 25 de junho de 2013.

Aprovado em 21 de novembro de 2013. 